\title{
FURTHER DIFFUSION TENSOR IMAGING CONTRIBUTION IN HORIZONTAL GAZE PALSY AND PROGRESSIVE SCOLIOSIS
}

\author{
Maria Conceptión García Otaduy', Claudia da Costa Leite', Lídia Mayumi Nagae ${ }^{1,2}$, \\ Marco da Cunha Pinho ${ }^{1,2}$, Clarissa Bueno ${ }^{3}$, Umbertina Conti Reed ${ }^{3}$, Fernando Kok ${ }^{3}$
}

\begin{abstract}
In two siblings with clinical diagnosis of horizontal gaze palsy associated with progressive scoliosis (HGPPS) we could demonstrate by diffusion tensor imaging: (1) An anterior displacement of the transverse pontine fibers; (2) Posterior clumping of the corticospinal, medial lemniscus and central tegmental tracts and of the medial and dorsal longitudinal fasciculi complex; (3) Absent decussation of superior cerebellar peduncle. Those findings can contribute as surrogate markers for the diagnosis.
\end{abstract}

KEY WORDS: diffusion, scoliosis, palsy, MRI.

\begin{abstract}
Contribuição adicional das imagens por tensores de difusão em paralisia do olhar conjugado horizontal associada a escoliose progressiva

Resumo - Em dois irmãos com diagnóstico clínico de paralisia do olhar conjugado horizontal associada a escoliose progressiva, foi possivel determinar através de imagens por tensores de difusão: (1) Deslocamento anterior das fibras pontinas transversas; (2) Agrupamento posterior do trato córtico-espinhal, lemnisco medial e trato tegmentar central e complexos dos fascículos longitudinais medial e dorsal; (3) Ausência da decussação dos pedúnculos cerebelares superiores. Tais achados podem contribuir como marcadores para o diagnóstico.
\end{abstract}

PALAVRAS-CHAVE: difusão, escoliose, paralisia, RM.

Horizontal gaze palsy associated with progressive scoliosis (HGPPS) is a rare autosomal recessive disease that has been recently shown to be caused by mutations in the $R O B O 3$ gene of the roundabout family, on chromosome 11q23-25 $5^{2}$ which product is involved in axon guidance processes. Conventional MR imaging shows hindbrain dysplasia ${ }^{3,4}$ with findings that are very supportive of the pathophysiology of the disease, which is thought to involve the medial longitudinal fasciculus (MLF) and adjacent areas of the abducens nuclei and paramedian pontine reticular formation (PPRF).

Diffusion tensor imaging (DTI), with its ability to demonstrate white matter tracts, is a very suitable technique to further evaluate the abnormalities underlying this disease. Previous DTI studies have described absence of superior cerebellar and pyramidal decussations, absence of major pontine fibers and absence of the decussation of the superior cerebellar peduncles (DSCP), with fMRI combined study confirming ipsilateral sensorymotor findings.

In this study, two siblings with HGPPS are shown in whom fiber tracking allowed identification of the transverse pontine fibers anteriorly displaced and resolution of the corticospinal tract (CST) and the ascending sensory tracts (AST).

\section{METHOD}

Data were obtained at a 1.5 T scanner, 9.1 Signa Horizon LX (GE Healthcare; Milwaukee, USA). DTI acquisition consisted of a diffusion-weighted spin-echo (SE) pulse sequence with a singleshot echo-planar imaging (EPI) read-out [TR/TE of 12,600/88.6 $\mathrm{ms} ; \mathrm{FOV} /$ phase FOV/NEX of $260 \mathrm{~mm} / 100 \% / 3$ ]. Forty-five 3 $\mathrm{mm}$ thick axial slices parallel to the anterior comissure-posterior comissure (AC-PC) line were acquired covering the entire brain. The maximum b value was $1,000 \mathrm{~s} / \mathrm{mm}^{2}$, applied in a $15 \mathrm{dif}$ -

\footnotetext{
'Department of Radiology, Hospital das Clínicas da Faculdade de Medicina da Universidade de São Paulo (HC-FMUSP), São Paulo SP, Brazil; ${ }^{2}$ Department of Radiology, Hospital Israelita Albert Einstein, São Paulo SP, Brazil; ${ }^{3}$ Department of Neurology, Division of Pediatric Neurology, Hospital das Clínicas da Faculdade de Medicina da Universidade de São Paulo (HC-FMUSP), São Paulo SP, Brazil.
}

Received 4 February 2009, received in final form 5 August 2009. Accepted 3 September 2009.

Dra. Lídia Mayumi Nagae - Hospital Israelita Albert Einstein / Radiology - Av. Albert Einstein 627 / 701 - $05651-901$ São Paulo SP - Brasil. E-mail: lidiamayumi@gmail.com 
ferent gradient direction scheme along with 3 reference images with minimal diffusion-weighting $(b=0)$. Imaging matrix was 64 $\times 64$, zerofilled to a $256 \times 256$ matrix, rectangular FOV of $80 \%$. Scan time was 8 min $52 \mathrm{sec}$.

Patients had also routine clinical pulse sequences, including fat-saturated axial T2-weighted [TR/TE/acquisition time 4,900/102 msec/1 minute 03 seconds] and fluid-attenuated inversion recovery (FLAIR) [TR/TE/IT/ acquisition time 10,000/100/2,200/2 minutes 20 seconds] sequences. Patient 2 had also 3D-SPGR volumetric sequence [flip angle/TE/ acquisition time $15^{\circ} / 1.7$ seconds $/ 2$ minutes 35 seconds]. Patient 1 could not tolerate this last sequence. Fibertracking was performed using fiber assignment continuous tracking (FACT) with a "brute force" approach, with ROls drawn on the pre-central and postcentral gyri, as well as on the anteriorly displaced transverse pontine fibers and superior cerebellar peduncle (SCP).

\section{Cases}

Patient 1 - A 7-year-old female, born to first cousin parents, after uneventful pregnancy and labor. At 3 months of age, their parents recognized her inability to look laterally, and because of common up and downward eye movements, she was misdiagnosed as having seizures. A progressive and debilitating scoliosis ensued after 1 year of age, and neurological examination disclosed lateral eye gaze palsy. Her development was otherwise normal.

Patient 2 - Is the 2-year-old brother of patient 1, born after uneventful pregnancy and labor. He had neonatal jaundice treated with phototherapy. Early in life it was recognized conjugate gaze paralysis, lateralizing the head to follow objects. Neurolog- ical examination disclosed global developmental delay and conjugate gaze paralysis, with preservation of vertical eye pursuit.

\section{RESULTS}

Both patients presented with similar findings on conventional MRI and DTI sequences, also similar to the ones already reported in the literature, which included flattening of the basis pontis with a posterior midline cleft (split pons sign), hypoplasia of the pontine tegmentum and a butterfly or rectangular-shaped medulla oblongata with anterior flattening, the olives being more prominent than the pyramids ${ }^{3,4}$. DTI findings showed striking abnormal findings on the color-coded maps of the posterior fossa structures. Usually, the transverse pontine fibers (TPF) assume a red color as the fibers run laterolaterally, separating the CST anteriorly from the medial lemniscus (ML)/central tegmental tract (CTT) and medial and dorsal longitudinal fasciculi (MDLF) complex posteriorly (Fig G) nominated $\mathrm{AST}^{5}$. In our patients, the TPF are anteriorly displaced, with clumping of the remaining blue-colored tracts (cranio-caudal orientation of the fibers) posteriorly (Fig D, F). ROI placed on the pre-central gyrus (in turquoise on Fig A-D) delineated the CST. Placement of another ROI on the post-central gyrus (in pink on Fig D) delineated a tract which penetrated the thalamus and could be seen in a lateral position on the mesencephalon, assuming the trajectory of the ascending sensory pathways. Fiber tracking allowed, thus, identification of the tracts forming the posterior clumping of blue-colored tracts and the CST to be resolved from
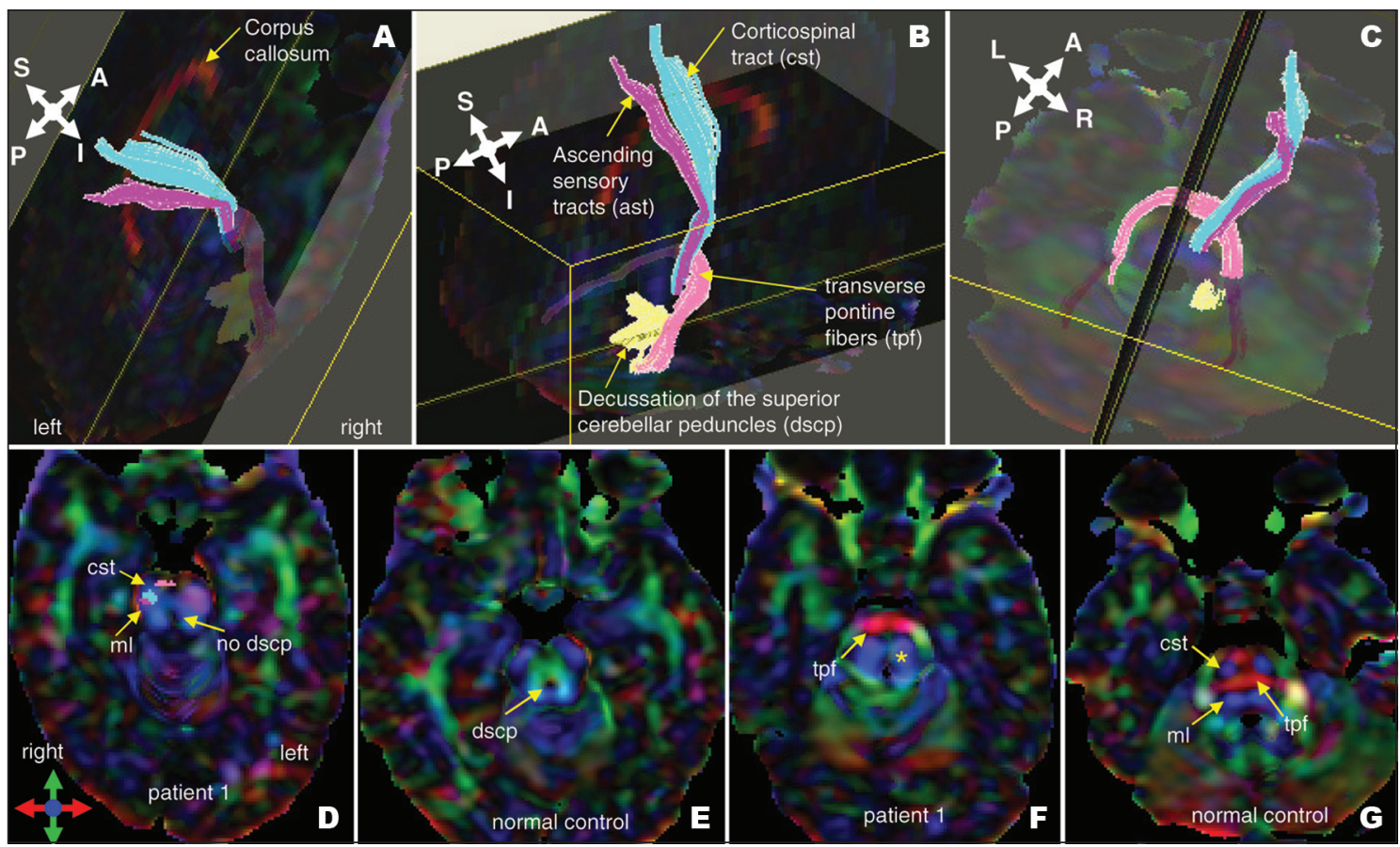

Figure. [A-C] Patient 1: fibertracking. TPF, CST and ML. [D-G] color-coded maps [D,E,F,G]. [D,F] Patient 1: absence of DSCP; anteriorly displayed TPF (arrow); clumping of CST and ML/CTT and MDLF complex (asterisk); [E,G] normal control. 
the ML/CTT/MDLF complex, which was posteriorly and laterally displayed (Fig $\mathrm{A}-\mathrm{C}$ ) at the pons level. No red dot of the DSCP, which is normally seen on colorcoded maps (Fig E), could be shown in our patients (Fig D).

\section{DISCUSSION}

Abnormalities in conjugate horizontal eye movement have been described in association with progressive scoliosis ${ }^{1,6}$. Absence of conjugate horizontal eye movement are thought to be congenital, even though in some case reports, clinical evaluation during childhood had been normal or neglected this finding. Progressive scoliosis is seen to develop in childhood or adolescence.

There have been no autopsy studies reported, however neurological examination, neurophysiological and imaging studies have contributed to speculate about the sites of lesions in this disease. The fact that horizontal conjugate eye movement paralysis is seen without esotropia or lateral rectus muscle atrophy favors the site of lesion to reside at the MLF rather than on the abducens nuclei. Contrary to what is seen in Moebius syndrome, in HGPPS, typically, the VII nerve is not involved, also favoring sparing of the abducens nucleus as the VII nerve turns around it and lesions of the last site invariably course with associated facial involvement. Vestibular-ocular reflex (VOR) and optokinetic nystagmus (OKN) are reported to be absent in $\mathrm{HGPPS}^{6}$, while vertical saccades and pursuit are normal, favoring involvement of MLF to PPRF lesion. PPRF lesion would also promote vertical saccades and pursuit derangements. Previous somato-sensory evoked potential studies have demonstrated evidence of uncrossed descending corticospinal motor and dorsal column-medial lemniscal pathways.

Lower brainstem abnormalities with lesions in gracilis, lateral vestibular nucleus, superior colliculus as well as of the dorsal longitudinal fasciculus have been shown to cause kyphoscoliosis in rats ${ }^{7}$, what could account for the progressive scoliosis seen in the HGPPS patients.

On MR imaging ${ }^{3,7}$, although normal studies were previously reported, the most characteristic features encountered concurred with proposed physiopathologic and pathologic mechanisms in the disease, with a posterior midline cleft in the pons (split pons sign) potentially reflecting involvement of the abducens nerve nuclei, the MLF and/or the PPRF; the butterfly or rectangular-shaped medulla oblongata with anterior flattening, and the olives more prominent than the pyramids reflecting the absence of decussation of the pyramids. The tent-shaped floor of the IVth ventricle is thought to reflect absence of the protrusions determined by the abducens, gracile and cuneate nuclei on the posterior aspects of the pons and medulla, respectively.
Recently, HGPPS has been shown to be caused, in some patients, by mutations in the $\mathrm{ROBO} 3$ gene of the roundabout family, on chromosome 11q23-252. Proteins encoded by these genes are thought to be involved in axon guidance processes and the patients described presented absence of superior cerebellar and pyramidal decussations using $\mathrm{DTI}^{8}$. On the color-coded maps ${ }^{9}$, absence of major pontine fibers and absence of the DSCP were recently demonstrated in a patient with the $\mathrm{ROBO} 3 \mathrm{mu}$ tation. In our patients, DTI study has demonstrated that the transverse pontine fibers (TPF) are actually anteriorly displaced. In addition, tractography has been useful to demonstrate that the posteriorly clumped tracts include the CST and the ML/CTT and MDLF complex. One recent study combined fMRI, DTI and neurophysiological evaluations confirming ipsilateral sensorymotor findings ${ }^{10}$.

Some previously reported patients have been mentioned to present absence of convergence, facial paralysis or facial myokimia which may suggest a more widespread brainstem lesion in some patients, with the possibility that a spectrum of abnormalities might be included.

Even in previous cases reported in whom conventional MR imaging findings were normal, DTI could have potentially contributed to the diagnosis, showing the abnormal disposition of fibers in the pons. We sustain that the anatomical information given by DTI study could contribute to the diagnosis of HGPPS as a surrogate marker of the disease in patients where genetic studies are still difficult to obtain.

\section{REFERENCES}

1. Dretakis EK, Kondoyannis PN. Congenital scoliosis associated with encephalopathy in 5 children of two families. JBJS 1974;56:1747-1750.

2. Jen JC, Chan WM, Bosley TM, et al. Science 2004;304:1509-1513.

3. Pieh C, Lengyel D, Neff A, Fretz C, Gottlob I. Braisntem hypoplasia in familial horizontal gaze palsy and scoliosis. Neurology 2002;59:462-463.

4. Rossi A, Catala M, Bianchieri R, Di Comite R, Tortori-Donati P. MR imaging of brain-stem hypoplasia in horizontal gaze palsy with progressive scoliosis." AJNR Am J Neuroradiol 2004;25:1046-1048.

5. Nagae-Poetscher LM, Hangyi J, Wakana S, Golay X, van Zijl PCM, Mori $\mathrm{S}$. High-resolution diffusion tensor imaging of the brain stem at $3 \mathrm{~T}$. AJNR Am J Neuroradiol 2004;25:1325-1330.

6. Sharpe JA, Silversides JL, Blair RDG. Familial paralysis of horizontal gaze associated with pendular nystagmus, progressive scoliosis, and facial contraction with myokimia. Neurology 1975;25:1035-1040.

7. Santos AV, Matias S, Saraiva P, Goulão A. MR imaging features of brain stem hypoplasia in familial horizontal gaze palsy and scoliosis. AJNR Am J Neuroradiol 2006;27:1382-1383.

8. Mori H. Fijishiro T, Hayashi N, et al. Partially uncrossed pyramidal tracts shown by tractography in horizontal gaze palsy and scoliosis. AJR 2004;185:4-6.

9. Sicotte NL, Salamon G, Shattuck DW et al. Diffusion tensor MRI shows abnormal brainstem crossing fibers associated with $\mathrm{ROBO} 3$ mutations. Neurology 2006;67:519-521.

10. Haller S, Wetzel AG, Lütschg J. Functional MRI, DTI and neurophysiology in horizontal gaze palsy with progressive scoliosis. Neuroradiology 2008;50:453-459. 